\title{
Effects of Using Hypermedia on Learning Some Football (Soccer) Basic Skills for the First Year Students, Faculty of Physical Education for Men - Al-Azhar University
}

\author{
Ebraheem Al-Metwally Ahmed*, Safwat Mabrouk Mahmoud**
}

\begin{abstract}
:
The current research aims at preparing an educational software using hypermedia for learning (ball absorption - maneuvering - shooting - goalkeepers' skills) in football for students of the faculty of physical education - Al Azhar University and identifying its effects on learning these skills. The researchers used the quasi-experimental approach (two-group design) with pre-and post- measurements on a sample of (120) students of the first year-faculty of Physical Education for Men - Al-Azhar University. Sample was divided into two groups (experimental/control) with (60) students in each group. The researchers concluded that the recommended educational program has a positive effect on learning the technical performance of basic football skills under investigation as learning with hypermedia led to positive effects compared with traditional methods of teaching and saved time and effort and has a positive effect on guiding performance and correcting errors.
\end{abstract}

Keywords: hypermedia-football (soccer) - basic skills

\section{Background and Research Problem:}

E ducational technology is an organized process that aims at enhancing human learning and is based on human interaction with various sources of learning like material, equipments and devices. This works on problem solving in learning situations in addition to achieving specific learning goals. Hypermedia and multimedia represent an educational system including various materials that integrate and interact functionally in an educational program to achieve its aims. Organizing these tools in a gradual controlled arrangement helps each learning to proceed in the educational program according to his/her own capabilities in a positive manner, in addition to choosing educational materials suitable for such capabilities (1).

Technology is a basic requirement for

* Assistant Professor, Faculty of Physical Education for Men, Al-Azhar University, Egypt.

** Lecturer, Faculty of Physical Education for Men, Al-Azhar University, Egypt. developing and improving educational systems and enhancing various aspects of teaching and learning. The concept of systems means that various parts of the system interact to achieve one or more goals. Using systems in physical education changed the way we view technological aids like computers, educational television, closed television circuits and educational films. These aids are now considered as basic components of the technological system of education and training inside the general educational framework (2).

Developments in modern technologies like satellites, live TV and radio broadcast and educational videos led to a vast and quick spread of knowledge. This, in turn, has various effects on various aspects of life in modern societies, especially educational systems. Therefore, developing and improving these technologies became a major competitor for the traditional role of schools. The traditional vision of the classroom is no longer suitable for this age and depending solely on the teacher for delivering knowledge is no longer good enough. 
In addition, traditional curricula, depending on memorization and instruction without encouraging critical thinking or even providing chances for creativity and exploration to improve gifts and attitudes of learners, are no longer suitable for this fast changing age with all its technological developments in all aspects of life, science and knowledge (3).

Hypermedia is modern technology in education that helps learners to interact positively with technological aids through computer sets. It helps achieving educational goals effectively as it provides learners with photos, animations, illustrations, video clips, sound effects and various types and sizes of writing fonts with different shapes and colors. The concept of hypermedia is closely related to two major principles; integration and interaction. In other words, it integrates various educational media in one interactive educational program $(4,5)$.

Hypermedia is a modern educational technology that represents an interactive educational system through computer software to achieve specific goals. This technology is based on a progressive controlled arrangement that helps each learner to proceed according to his/her own characteristics and to be positive and active throughout the program. This technology is very important in learning various motor skills as it provides learners with opportunities to perceive the successive phases of skill performance through clear vision and enough time for watching various models included in the system (6).

The sports field is highly affected by modern technological advances as using modern educational technology to improve the cognitive and technical levels of learners has become a major interest among physical education experts. This led to developing various methods and approaches for teaching as physical education teachers can use various ways to transfer knowledge and information to learners to achieve the best possible cognitive and technical levels (7).

Football (soccer) is a sport that requires a high technical performance level due to the variety of its skills (kicks - ball dribbling - ball control outside throw - head kicks - maneuvering attack - goal keepers' skills), in addition to various performance situations and various tasks required from the player in the field (attack/defense duties). It requires specific physical, technical and mental abilities and skills in addition to specific psychological characteristics that help players to deal with all these situations in the field.

Mastering basic skills is a major component of the team success in fulfilling the required duties during the match. When teach such skills, a teacher should master them faultlessly to be able to teach them correctly and to correct any kind of technical faults a learner may develop as the teacher is responsible for teaching learners according to sound bases of knowledge to develop their technical and physical levels.

Physical fitness is a major component for improving the performance level of football players on all its levels (youth - adults professionals). It is used for youth to help them improve their physical structure and learn body balance. These factors are critical for improving the sports capabilities of young players in addition to improving their cognitive and motivational aspects toward involving in football. Without mastering the basic skills, a player can never achieve an advanced performance level (8).

Football (soccer) is popular sports among all ages and both sexes. It is considered as a good investment of free time in a useful activity. This makes football a very important educational activity that works on preparing an integrated well-balanced character for each learner.

Through supervising the practices of football basics at the faculty of physical education - AlAzhar University, the researchers noticed the poor performance level of students due to the lack of motivation and the poor involvement in practices due to the large number of students and lack of time to perform and practice each skill using the traditional way of instruction for such skills. Due to modern technology application, the increase of students' numbers and insufficient time for practicing, the traditional methods of teaching lead to poor performance. In addition, these methods do not increase students' motivation and enthusiasm.

The researchers think that this problem can be solved through using hypermedia as modern technology in teaching physical education in 
general, and especially in teaching football (soccer) skills.

\section{Literature Review:}

Abd El-Fattah Refaat (2007) studied the effect of a training program using hypermedia on the performance level of some basic tennis strokes for junior tennis players. He used the quasiexperimental approach on sample of (22) junior tennis players. He indicated that using the recommended hypermedia program improved the performance level of some basic tennis strokes for junior tennis players under investigation (9).

Ghada Mohamed Yousef (2007) studied the effect of a training program using hypermedia on the performance level of some basic ballet skills. She used the quasi-experimental approach on sample of (38) college ballet performers. She indicated that using the recommended hypermedia program improved the performance level of some basic ballet skills under investigation (10).

Ghaida Abd El-Shakour Mohamed (2008) studied the effect of a training program using hypermedia on learning the forward Salto for female gymnastics performers. She used the quasi-experimental approach on sample of (40) college gymnastics performers. She indicated that using the recommended hypermedia program had positive effects on learning the forward Salto for female gymnastics performers under investigation. (11).

Maisa Mohamed Afify (2008) studied the effect of a training program using hypermedia on learning the back crawl stroke for college female swimmers. She used the quasiexperimental approach on sample of (274) college female swimmers. She indicated that using the recommended hypermedia program had positive effects on learning the back crawl stroke for college female swimmers under investigation (12).

Abd El-Rahman Hasan (2008) studied the effect of a training program using hypermedia on learning the shot pot for technical schools students. He used the quasi-experimental approach on sample of (30) male technical schools students. He indicated that using hypermedia has positive effects on learning the shot pot for technical schools students under investigation (13).

Mona Mohamed Nageeb (2009) studied the effect of a training program using hypermedia on learning some hoop skills for female gymnastics performers. She used the quasiexperimental approach on sample of (38) college gymnastics performers. She indicated that using the recommended hypermedia program had positive effects on learning some hoop skills for female gymnastics performers under investigation (14).

Hany Ahmed Sabry (2009) studied the effect of a training program using hypermedia on learning some handball skills for preparatory schools students. He used the quasiexperimental approach on sample of (20) male preparatory schools students. He indicated that using hypermedia has positive effects on learning some handball skills for preparatory schools students under investigation (15).

Ahmed Mohamed Abo Zaid (2010) studied the effect of a training program using hypermedia on the cognitive and performance levels of some handball skills for preparatory schools students. He used the quasi-experimental approach on sample of (30) male preparatory schools students. He indicated that using hypermedia has positive effects on the cognitive and performance levels of some handball skills for preparatory schools students under investigation (16).

Dina Metawlly Ahmed (2010) studied the effect of a training program using hypermedia on the performance level and anxiety for beginner children learning the dolphin stroke. She used the quasi-experimental approach on sample of (16) primary school male swimmers. She indicated that using the recommended hypermedia program had positive effects on the performance level and anxiety for beginner children learning the dolphin stroke under investigation (17).

Carr (2002) studied the effects of computerbased teaching on the learning of basic skills of physical education. He used the quasiexperimental approach on sample of (100) primary school male and female students. He indicated that computer-based teaching program 
was very effective compared to the traditional teaching in information recall after one day, two days and six weeks (18).

Ibanez et al (2003) designed computer software for evaluating and analyzing real time individual performance during training and competition for basketball players. They used the quasi-experimental approach on sample of (17) basketball players. Results indicated the validity of the recommended program in evaluating and analyzing real time individual performance during training and competition for basketball players (19).

Lada et al (2004) studied the use of computer in physical education programs for school and university students. They used the quasiexperimental approach on sample of (5) high school and university students. Results indicated the increase of physical fitness level of the sample due to practice in computer based programs (20).

Makasci et al (2004) studied the effects of using computer-based CDs on improving the ability to analyze football skills. They used the quasiexperimental approach on sample of (40) male university students. Results indicated that CDs were more effective than traditional instruction in improving the ability to analyze football skills (21).

Silva and Santana (2005) and discuss a methodology for the development of didactical materials for Physical Education and Sports based on information and communication technologies. The process begins with the analysis of the necessities, capabilities and expectations of the target public, follows with the development of the instructional design and ends with the method of structuring the development of the proposed didactical material. This method allows the construction of a complex hypermedia environment by means of a four stages process: conceptual modeling; navigation modeling; interface design and implementation. As a practical example, the researchers explained the development of Biomec, a hypermedia system also available on the Web that has got as it main goal interrelating the concepts of Sports and Basic Mechanics, in an area of the Biomechanics denominated (22).
Fayza Khdr (2010) studied the effect of using hypermedia on learning the first Kata in judo. The researcher used the recommended program on sample of female students in the faculty of physical education students -grade three-. The proposed education program using had a positive effect on learning the first Kata in judo (23).

\section{Aims:}

The current research aims at:

1. Preparing an educational software using hypermedia for learning (ball absorption maneuvering - shooting - goalkeepers' skills) in football for students of the faculty of physical education - Al Azhar University.

2. Identifying the effects of using hypermedia on learning (ball absorption - maneuvering shooting - goalkeepers' skills) in football for students of the faculty of physical education Al Azhar University

3. Saving time and effort during practical teaching of the skills under investigation for students of the faculty of physical education Al Azhar University.

4. Increasing students' awareness and perception of the importance of modern technologies and its role in teaching and learning.

\section{Hypotheses:}

1. There are statistically significant differences between the pre- and post- measurements of the control group learning outcomes of (ball absorption - maneuvering - shooting goalkeepers' skills) in favor of the postmeasurements.

2. There are statistically significant differences between the pre- and post- measurements of the experimental group learning outcomes of (ball absorption - maneuvering - shooting goalkeepers' skills) in favor of the postmeasurements.

3. There are statistically significant differences between the post- measurements of the control and experimental groups learning outcomes of (ball absorption - maneuvering - shooting - 
goalkeepers' skills) in favor of the experimental group.

\section{Methods:}

\section{Approach:}

The researchers used the quasi-experimental approach (two-group design) with pre- and postmeasurements.

\section{Community and Sample:}

Research community included (900) students. Sample $(n=200)$ was purposefully chosen from the first year students - faculty of Physical Education for Men - Al-Azhar University. (80)
Students were excluded from the main sample according to the following criteria:

- Grade repeaters who already learned the football skills under investigation $(n=25)$.

- Football players registered in the Egyptian federation of football $(n=13)$.

- Pilot study sample ( $n=22)$.

- Calibration sample for tests $(n=20)$.

- The main sample included only (120) students divided into two (experimental/control) groups (60 students each). Table (1) shows sample description.

Table (1)

Sample description

\begin{tabular}{|c|c|c|c|c|c|c|}
\hline \multirow{2}{*}{ Group } & \multirow{2}{*}{ Sample } & \multicolumn{4}{|c|}{ Excluding } & \multirow{2}{*}{ Total } \\
\cline { 3 - 7 } & & Repeaters & Players & Calibration & Pilot & \\
\hline Experimental & 60 & 15 & 7 & 12 & 15 & 109 \\
\hline Control & 60 & 10 & 6 & 8 & 7 & 91 \\
\hline Total & 120 & 25 & 13 & 20 & 22 & 200 \\
\hline
\end{tabular}

\section{Data collection tools:}

1. A restameter for measuring heights and weights

2. Age (by months)

3. College official records for identifying registry status for each student

4. Data recording form for each student

5. IQ test (by Ahmed Zaky Saleh) (20)

6. Physical tests: $(100 \mathrm{~m}$ running.- Strength endurance test - Wide jump test - Agility test Flexibility test - Endurance (800m running) test)

7. Technical tests: (Maneuvering - Ball control Basic goalkeeper skills (ground ball catch - half fly kick) - Shooting)

\section{Pilot Study:}

The researchers performed a pilot study on pilot sample of (22) students from the same research community and outside the main sample to identify the following:

1. Validity of tools and equipments
2. Students' understanding for the experimental approach under investigation

3. Suitability of experimental setting

4. Suitability of the recommended program

5. Training assistants $(n=2)$ on using research tools and equipments.

Pilot study was performed from 24/10/2011 to 27/10/2011. Results verified all aims mentioned above.

\section{The Recommended Educational Program:}

\section{Aims:}

1. Preparing an educational software using hypermedia for learning (ball absorption maneuvering - shooting - goalkeepers' skills) in football for students of the faculty of physical education - Al Azhar University.

2. Identifying the effects of using hypermedia on learning (ball absorption - maneuvering shooting - goalkeepers' skills) in football for students of the faculty of physical education Al Azhar University 


\section{Purposes:}

- Providing students with (ball absorption maneuvering - shooting - goalkeepers' skills)

- Identifying the importance of basic football skills

- Students understand the nature of correct performance of football skills under investigation

- Increasing students' attention and concentration during performance

\section{Basics:}

- Considering growth aspects of students

- Considering the suitability of football skills under investigation with the age group and technical level of sample members

- Considering individual differences

- Considering progressive (from easy to difficult) principles of learning

- Motivating students through challenging their abilities

- Considering harmony of content and aims

- Providing students with equal opportunities to practice simultaneously

\section{Requirements:}

Football fields - goals with various sizes footballs (measure 4) - Sweden benches cones.

\section{Educational media used in the program:}

Illustrations - photos - tests - computer lab CDs

\section{The educational situation:}

The researchers prepared the educational situations through which the student is going to achieve goals of learning. They prepared a plan for using the available media according to its arrangement in the educational situation. Students are going to use media either individually or with peers under the teacher's supervision. Accordingly, the researchers prepared the program content through using hypermedia.

The researchers prepared the educational units $(n=8)$ to be delivered as one unit per week. Unit duration was (180) minutes with total duration of (24) hours for the whole program.

\section{Pre-Measurements:}

Pre-measurements were taken on 5-6/11/2011 for both groups and on all research variables.

\section{Main Application:}

The researchers applied the recommended program on the experimental group from $7 / 11 / 2011$ to $2 / 1 / 2012$ for (8) weeks (one unit per week).

\section{Post-Measurements:}

Post-measurements were taken on 3/1/2012 for both groups and on all research variables.

Statistical treatment:

Mean - standard deviation - Pearson's correlation coefficient - (t) test - improvement percentage. 
Results:

Table (2)

Difference significance between the pre- and post-measurements for the control group on technical variables (n=60)

\begin{tabular}{|c|c|c|c|c|c|c|c|c|}
\hline \multirow{2}{*}{ Variable } & \multicolumn{2}{|c|}{ Pre-test } & \multicolumn{2}{c|}{ Post-test } & \multirow{2}{*}{ Mean difference } & SD & (t) & Improvement (\%) \\
\cline { 2 - 9 } & Mean & SD & Mean & SD & & & \\
\hline Ground ball control & 3.7500 & 1.2572 & 6.4833 & .9654 & 2.7333 & 1.4714 & 14.389 & 72.9 \\
\hline Half fly kick & 2.0833 & .7874 & 3.9333 & .8206 & 1.8500 & .9356 & 15.316 & 88.8 \\
\hline Ball absorption & 14.5833 & 3.2275 & 27.8333 & 3.4893 & 13.2500 & 3.0288 & 33.886 & 90.9 \\
\hline Shooting & 1.4167 & .4972 & 2.5833 & .4972 & 1.1667 & .5574 & 16.212 & 82.3 \\
\hline Maneuvering & 33.0000 & 2.7184 & 27.5500 & 1.8358 & 5.4500 & 2.4316 & 17.361 & 16.5 \\
\hline
\end{tabular}

(t) table value on $p \leq 0.05=2.000$

Table (2) indicates a statistically significant measurement as improvement percentages difference between pre- and post- measurements ranged between (16.5\%) and (90.9\%). of the control group in favor of the post-

Figure (1)

Improvement percentages between the pre-and post-measurements for the control group on technical variables

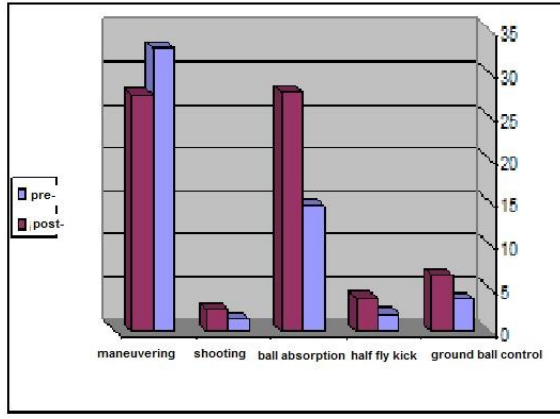

Figure (1) indicates the increase of post- control group for all research variables. measurements over pre-measurements of the

Table (3)

Difference significance between the pre-and post-measurements for the experimental group on technical variables $(n=60)$

\begin{tabular}{|c|c|c|c|c|c|c|c|c|}
\hline \multirow{2}{*}{ Variable } & \multicolumn{2}{|c|}{ Pre-test } & \multicolumn{2}{|c|}{ Post-test } & \multirow{2}{*}{ Mean difference } & SD & \multirow{2}{*}{$(\mathrm{t})$} & Improvement $(\%)$ \\
\cline { 2 - 9 } & Mean & SD & Mean & SD & & & \\
\hline Ground ball control & 3.9833 & .8732 & 8.1667 & 1.2645 & 4.1833 & 1.4555 & 22.264 & 105.0 \\
\hline Half fly kick & 2.2667 & .6342 & 5.2833 & 1.1511 & 3.0167 & 1.2953 & 18.040 & 133.1 \\
\hline Ball absorption & 15.3333 & 3.4280 & 32.0000 & 3.4690 & 16.6667 & 3.8693 & 33.365 & 108.7 \\
\hline Shooting & 1.5333 & .5957 & 3.2500 & .6796 & 1.7167 & .7152 & 18.591 & 112.0 \\
\hline Maneuvering & 32.5333 & 3.7573 & 17.4167 & .9441 & 15.1167 & 3.9104 & 29.944 & 46.5 \\
\hline
\end{tabular}

(t) table value on $p \leq 0.05=2.000$

Table (3) indicates a statistically significant measurement as improvement percentages difference between pre- and post- measurements ranged between $(46.5 \%)$ and $(133.1 \%)$.

of the experimental group in favor of the post- 
Figure (2)

Improvement percentages between the pre- and post-measurements for the experimental group on technical variables

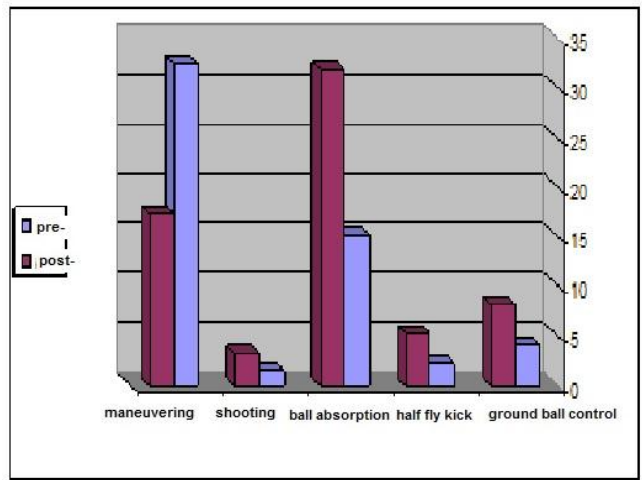

Figure (2) indicates the increase of post- experimental group for all research variables. measurements over pre-measurements of the

Table (4)

Difference significance between the post-measurements for the control and experimental group on technical variables

\begin{tabular}{|c|c|c|c|c|c|}
\hline \multirow{2}{*}{ Variable } & \multicolumn{2}{|c|}{ Control } & \multicolumn{2}{c|}{ Experimental } & \multirow{2}{*}{$(\mathrm{t})$} \\
\cline { 2 - 5 } & Mean & SD & Mean & SD & \\
\hline Ground ball control & 6.4833 & .9654 & 8.1667 & 1.2645 & 8.196 \\
\hline Half fly kick & 3.9333 & .8206 & 5.2833 & 1.1511 & 7.397 \\
\hline Ball absorption & 27.8333 & 3.4893 & 32.0000 & 3.4690 & 6.560 \\
\hline Shooting & 2.5833 & .4972 & 3.2500 & .6796 & 6.133 \\
\hline Maneuvering & 27.5500 & 1.8358 & 17.4167 & .9441 & 38.02 \\
\hline
\end{tabular}

(t) table value on $p \leq 0.05=1.980$

Table (4) indicates a statistically significant the control experimental group in favor of the difference between the post- measurements of experimental group.

Figure (3)

Improvement percentages between the post-measurements for the control and experimental group on technical variables

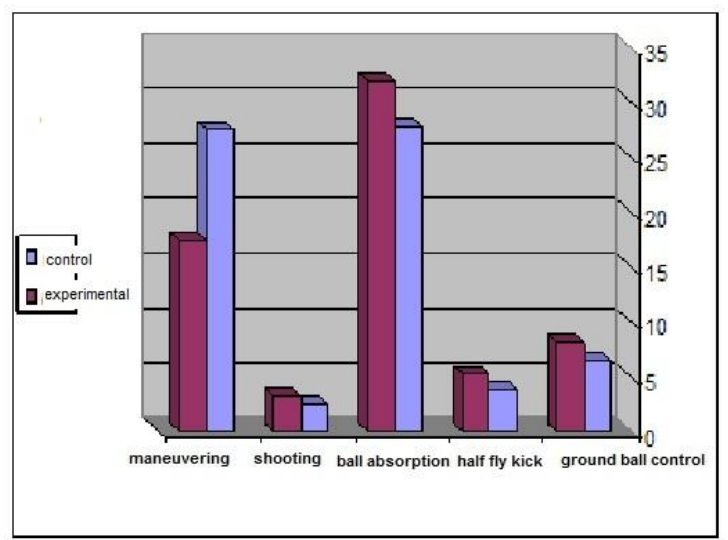

Figure (3) indicates the excellence of the all research variables. experimental group over the control group for 


\section{Discussion:}

Results of the experimental group, shown in table (3) indicated statistically significant differences between the pre- and postmeasurements in favor of the postmeasurements as (t) values ranged between (18.040) and (33.365). The researchers think that this is due to using hypermedia as it has positive effects on improving the performance level of students. As for catching ground balls, pre-measurement mean, post-measurement mean and $(\mathrm{t})$ value were $3.983,8.166$ and 22.26 respectively. As for half fly kick, premeasurement mean, post-measurement mean and $(\mathrm{t})$ value were 2.266, 5.283 and 18.040 respectively. For ball absorption, premeasurement mean, post-measurement mean and (t) value were 15.333, 32 and 33.365 respectively. For shooting; pre-measurement mean, post-measurement mean and $(\mathrm{t})$ value were $1.533,3.250$ and 18.591 respectively. For maneuvering, pre-measurement mean, postmeasurement mean and $(\mathrm{t})$ value were 32.5333 , 17.416 and 29.944 respectively.

Results of the control group, shown in table (2) indicated statistically significant differences between the pre- and post-measurements in favor of the post-measurements as $(\mathrm{t})$ values ranged between (15.316) and (33.886). This indicates some improvement of the performance level of students in this group. However, this improvement was less than what is noticed in the experimental group. Difference significance between the pre- and post-measurements of the control group for the skills under investigation (catching ground balls - half fly kick - ball absorption - shooting - maneuvering) were $(2.733-1.850-13.25-1.166-5.45)$ respectively.

Table (4) indicated statistically significant differences between the two groups on all research variables in favor of the experimental group as (t) values ranged between (6.133) and (38.02). Difference significance between postmeasurements of the control and experimental groups for the skills under investigation (catching ground balls - half fly kick - ball absorption - shooting - maneuvering) were $(8.196-7.397-6.56-6.133-38.025)$ respectively. This is in agreement with previous studies indicating the effective role of hypermedia in improving the technical performance level of basic sports skills. $(11,12$, $13,14,15,16,17,18,19)$ The researchers think that these results are due to the effectiveness of hypermedia in increasing students' motivation towards practice and its effective role in dealing with individual differences among students.

The effect of using hypermedia was clear as the improvement percentages between pre- and post measurements for the control and experimental groups were between (16.5\%-90.9\%) and (46.5\%-133.1\%) respectively. Improvement of the performance level for the control group is considered weak, compared to the experimental group. This is due to the use of hypermedia with the experimental group, leading to this improvement. The researchers noticed that students of the experimental group were happy with using hypermedia and their absence decreased, indicating that hypermedia has positive effects on learning the skills under investigation.

\section{Conclusions:}

The researchers concluded the following:

1. The recommended educational program has a positive effect on learning the technical performance of basic football skills under investigation.

2. Learning with hypermedia led to positive effects compared with traditional methods of teaching.

3. The recommended educational program saved time and effort and has a positive effect on guiding performance and correcting errors.

4. The recommended educational program increased students' awareness of modern technology and decreased their fears of using modern technology.

5. The recommended educational program has positive effects, compared with traditional program, on improving the technical performance of basic football skills under investigation as $(\mathrm{t})$ values ranged between (18.040) and 33.365) in favor of the experimental group. 
6. The recommended educational program has positive effects, compared with traditional program, on improving the technical performance of basic football skills under investigation as improvement percentages were between $(16.5 \%-90.9 \%)$ for the control group and $(46.5 \%-133.1 \%)$ for the experimental group.

7. The recommended program using hypermedia plays a major role in students' awareness of the effectiveness of modern technology in teaching and learning and making it more attractive and interesting.

8. The recommended program using hypermedia plays a major role in saving time and effort, in addition to performing the specific tasks more quickly and accurately

\section{Recommendations:}

The researchers recommend the following:

1. Using hypermedia in learning basic football skills for students of the faculty of physical education - Al-Azhar University

2. Preparing hypermedia for learning other football basic skills for students of the faculty of physical education - Al-Azhar University

3. The ministry of higher education and other governmental bodies should work on providing faculties of physical education with modern technologies and computer labs

4. Providing faculties of physical education with modern facilities and equipments to facilitate their mission and improve learning outcome

5. Performing further similar research on other age groups

6. Using results of technical skills tests to identify the technical performance level of students

7. Performing further similar research on other sports

\section{References:}

1. Radwan, Bothaina M. (1993): Technology in teaching and learning, 2nd ED. Dar Al-Sharq Amman - Jordan (in Arabic). PP: 25, 38-39
2. Al-Sayed, Atef (2000): Educational and information technologies and the use of computer and video in learning and teaching. Ramadan Press - Alexandria - Egypt (in Arabic). P:26

3. Baghdady, Mohamed R. (1998): Taching and learning Technology, 2nd ED. ED. Dar Al-Fikr Al-Araby - Cairo - Egypt (in Arabic). P: 75

4. Mohamed, Mosataf, A. (1999): Educational technology: Arabic Studies. Markaz Al-Ketab Cairo - Egypt (in Arabic) P: 129

5. Kandeel, Yaseen A. (1999): Teaching Aids and educational technology: content, relation and classification. Dar Al-Nashr Al-Dawly KSA (in Arabic) P: 251

6. Fahmy, Zinab (1981): Volleyball, Part 1. Dar Al-Maaref - Cairo - Egypt (in Arabic). P:214

7. Abdalla, Ahmed M. (1995): Effects of using hypermedia on the cognitive and technical levels of some basic basketball skills. $\mathrm{PhD}$ thesis, Faculty of Physical Education - Helwan University - Egypt (in Arabic). P: 32

8. Abd El-Kareem, Mahmoud A. (2006): Dynamics of teaching physical education, 1st ED. Markaz Al-Ketab - Cairo - Egypt (in Arabic) P:7

9. Al-Khouly, Amin A. (2009): Educational technology and sports training (educational materials - training equipments). 1st ED. Dar Al-Fikr Al-Araby - Cairo - Egypt (in Arabic). P: 38

10. Hasan, Zaky M. (2001): Modern techniques in teaching and instructing volleyball. Moltaqa Al-Fikr - Alexandria - Egypt (in Arabic) P:48

11. Abd El-Fattah, Abd El-Fattah R. (2007): Effects of using hypermedia on the performance level of some basic tennis strokes for junior tennis players. Master thesis, Faculty of Physical Education - Tanta University - Egypt (in Arabic). P: 11

12. Al-Sayed, Ghada M. (2007): Effects of using hypermedia on the performance level of some basic skills in ballet. Master thesis, Faculty of Physical Education - Zagazig University - Egypt (in Arabic). P: 132

13. Mohamed, Ghaida A. (2008): Effects of using hypermedia on learning forward Salto in gymnastics. Master thesis, Faculty of Physical 
Education - Zagazig University - Egypt (in Arabic). P: 124

14. Al-Sayed, Maisa M (2008): effects of using hypermedia on learning the back crawl stroke for beginners. Master thesis, Faculty of Physical Education - Helwan University - Egypt (in Arabic). P: 137

15. Abd El-Rahman, Medhat Y. . (2009): Effects of using hypermedia on learning shot pot for technical school students. Master thesis, Faculty of Physical Education - Zagazig University - Egypt (in Arabic). P: 12

16. Al-Nagar, Mona M. . (2009): Effects of using hypermedia on learning hoop skills in gymnastics. Master thesis, Faculty of Physical Education - Zagazig University - Egypt (in Arabic). P: 114

17. Al-Hosainy, Hany A. . (2009): Effects of using hypermedia on learning handball skills for preparatory school students. PhD thesis, Faculty of Physical Education - Zagazig University Egypt (in Arabic). P: 120

18. Al-Helaly, Ahmed M. (2010): Effects of using hypermedia on the cognitive and technical levels of some basic handball skills. PhD thesis, Faculty of Physical Education - Mansoura University - Egypt (in Arabic). P: 98

19. Al-Metwally, Dina M. (2010): Effects of using hypermedia on the performance level and anxiety for beginner swimmers learning the dolphin stroke. . PhD thesis, Faculty of Physical
Education - Mansoura University - Egypt (in Arabic). P: 112

20. Carr,M.: Computer assisted instruction, in Elementary Physical Education D.A.I606a,2002

21. Ibanz S.J: Software for the basketball player's evaluation in real time. international yournal perform on ce and ysis in s university of wales insti7 cardiff, I Dwcember 2003

22. Lada,s,: Including Technology in Instructional programs,2004

23. Makasci,K,: Essects of Interactiv-Compu Based, CD Rom instruction on Ymproving psyvloment or Skill Analysis Ability of Soccer sk 2006

24. Silva, A. \& Santana, S. (2005). A Methodology for the Development of Didactical Software for the Physical Education and Sports. In P. Kommers \& G. Richards (Eds.), Proceedings of World Conference on Educational Multimedia, Hypermedia and Telecommunications 2005 (pp. 1660-1665). Chesapeake, VA: AACE

25. Khdr, Fayza Ahmad Mohamed (2010): Effects of Hypermedia on skills of first kata in judo. Procedia - Social and Behavioral Sciences, Vol5 , 2010, Pages 2242-2246

26. Saleh, Ahmed Zaky (1978): IQ picture test. Al-Alamia Press - Cairo - Egypt (in Arabic). PP: 
